\title{
Buckling length of a steel column for fire design
}

\author{
Fernando C.T. Gomes ${ }^{\text {a }}$, Paulo M. Providência e Costa ${ }^{a}$, João Paulo C. Rodrigues ${ }^{\text {a,* }}$, \\ Ildefonso C. Neves ${ }^{b}$ \\ ${ }^{a}$ Departamento de Engenharia Civil, Faculdade de Ciências e Tecnologia, Universidade de Coimbra, Polo II, Rua Luís Reis Santos, $3030-788$ Coimbra, Portugal \\ ${ }^{\mathrm{b}}$ Departamento de Engenharia Civil, Instituto Superior Técnico, Av. Rovisco Pais, 1049-001 Lisboa, Portugal
}

Received 15 June 2006; received in revised form 1 November 2006; accepted 16 November 2006

Available online 2 February 2007

\begin{abstract}
The Eurocode 3 part 1-2 gives some simple rules to determine the buckling length $l_{f i}$ of a steel column for fire design. In the case of a braced frame in which each storey comprises a separate fire compartment with sufficient fire resistance, Eurocode 3 suggests that the buckling length may be taken as $l_{f i}=0.5 \mathrm{~L}$ in an intermediate storey and as $l_{f i}=0.7 \mathrm{~L}$ in the top storey, where $L$ is the system length in the relevant storey.

Stability analyses for the evaluation of the buckling length and critical load of columns in braced frames show that the Eurocode 3 rule may be rather inaccurate in many practical situations. The authors propose alternative formulas to determine the buckling length at elevated temperatures, as an improvement of the actual rule of the Eurocode 3 part 1.2.
\end{abstract}

(C) 2006 Elsevier Ltd. All rights reserved.

Keywords: Steel; Fire; Buckling; Design; Column

\section{Introduction}

The buckling length of a column at elevated temperatures usually differs from that at room temperature [4]. The buckling length $l_{f i}$ of a column for fire design should be determined as for normal temperature design, considering the reduction of stiffness due to the elevated temperatures in elements exposed to fire.

However, in the case of braced frames, the Eurocode 3 part 1-2 [3] gives some simplified rules to determine the buckling length $l_{f i}$ of a column for fire design. In this case, Eurocode 3 determines the buckling length $l_{f i}$ of a column by considering it "as fixed in direction at continuous or semi-continuous connections to the column lengths in the fire compartments above and below, provided that the fire resistance of the building components that separate these fire compartments is not less than the fire resistance of the column" [3].

In the case of a braced frame in which each storey comprises a separate fire compartment with sufficient fire resistance, Eurocode 3 states that the following values for the buckling

\footnotetext{
* Corresponding author. Tel.: +351 239 797237; fax: +351 239797242.

E-mail address: jpaulocr@dec.uc.pt (J.P.C. Rodrigues).
}

length $l_{f i}$ of a continuous column may be taken:

- in an intermediate storey: $l_{f i}=0.5 \mathrm{~L}$

- in the top storey: $l_{f i}=0.7 \mathrm{~L}$

where $L$ is the system length in the relevant storey, see Fig. 1 .

The CEN Technical note 2.9 [2] was one of the background documents for the preparation of the Eurocode 3 part 1.2 in 1992, supporting the above definitions for the buckling length of columns in fire situations. Numerical simulations carried out by some of the authors of this document, for braced composite steel-concrete and for braced steel frames, led to different conclusions on how to calculate the buckling length to be used in the fire case. The numerical calculations carried out for composite steel-concrete frames have shown [2], that the values of $l_{f i}=0.5 \mathrm{~L}$ for an intermediate storey and $l_{f i}=0.7 \mathrm{~L}$ for the top storey, were the most appropriate for the determination of the buckling length in this type of element. However, the results of numerical simulations carried out for steel frames have shown [2], in the opinion of their authors, that "the reduction rules for the buckling length are less appropriate for steel frames". In that case it was proposed "to take the buckling length equal to the system height of the column". After some comparison of results, it was shown that this last consideration 


\begin{tabular}{ll|}
\multicolumn{2}{l}{ Notation } \\
$\alpha$ & stiffness ratio $\left(\alpha=K_{b} / K_{c}\right)$ \\
$\theta$ & steel temperature \\
$\eta_{1}$ & distribution factor at the top of the column \\
$\eta_{2}$ & distribution factor at the bottom of the column \\
$E$ & elastic modulus of steel at $20^{\circ} \mathrm{C}$ \\
$I$ & moment of inertia \\
$k_{E, \theta}$ & reduction factor for the elastic modulus of steel, \\
& dependent on the material temperature. \\
$K_{b}$ & beam stiffness coefficient \\
$K_{b i}$ & stiffness coefficient of beam $i$ \\
$K_{c}$ & column stiffness coefficient \\
$L$ & beam or column length \\
$l_{f i}$ & buckling length of a column in the fire situation \\
$l_{20}$ & buckling length at $20{ }^{\circ} \mathrm{C}$ \\
$l_{1200}$ & buckling length at $1200^{\circ} \mathrm{C}$ \\
$N_{f i, c r}$ & elastic critical load ( $\equiv$ Euler buckling load) in the \\
$\phi_{i}$ & fire situation \\
$\gamma$ & Livesley stability functions \\
$I_{c}$ & beam fire exposure parameter \\
$L_{c}$ & column moment of inertia \\
$u, \breve{u}$ & column length \\
& normalised axial load parameters for unexposed \\
$K$ & and exposed column lengths \\
& sub-assembly stiffness matrix
\end{tabular}

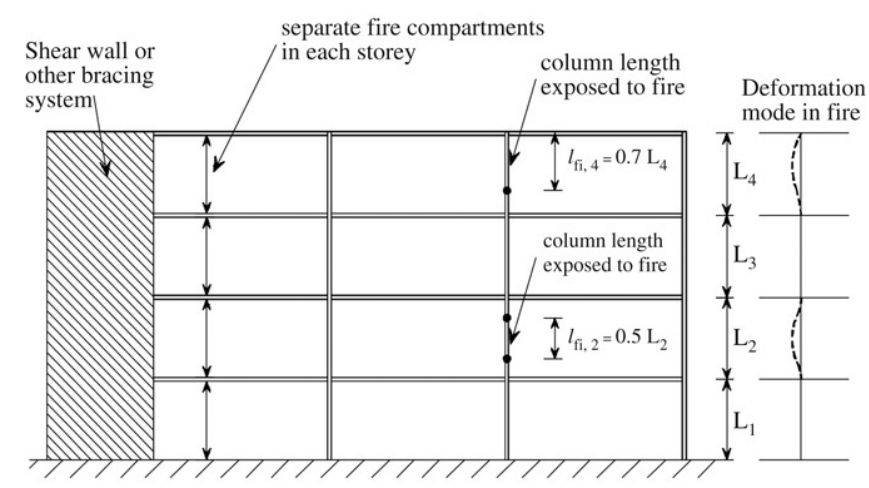

Fig. 1. Allowable buckling lengths $l_{f i}$ of columns in braced frames, according to Eurocode 3.

led to conservative solutions and the values from numerical simulations on composite frames were adopted.

The fire resistance of columns is very sensitive to column slenderness. Therefore, the correct evaluation of the column buckling length to be used in the calculations in case of fire is very important. Too conservative values are uneconomical. Unsafe values should not be used. Being aware of the importance of the problem, the authors have carried out several analytical simulations to determine if the proposal presented in the Eurocode 3 part 1.2 is the most appropriate for the determination of the buckling length of a steel column for the fire case. The results obtained have shown that the proposal of Eurocode 3 is not always on the safe side, mainly for steel temperatures lower than $600{ }^{\circ} \mathrm{C}$.

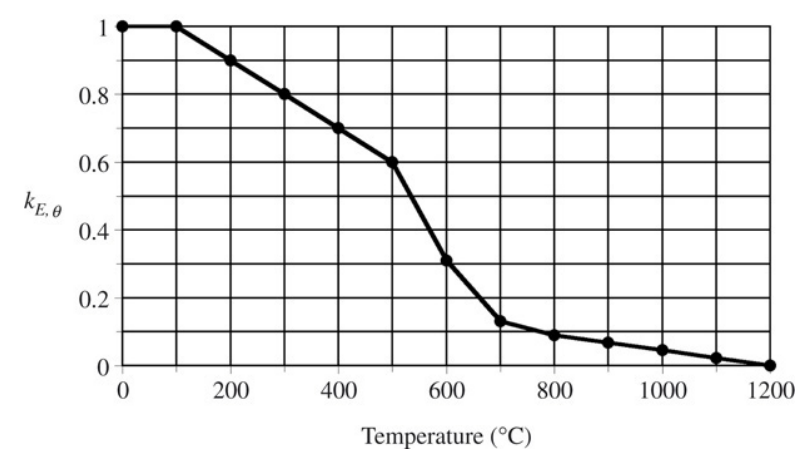

Fig. 2. Elastic modulus of steel as a function of the steel temperature.

The Eurocode 3 part 1.2 gives the reduction factor $k_{E, \theta}$ for the elastic modulus of steel at elevated temperatures, as represented in Fig. 2. In this and some of the following figures the dots represent the values computed at $100{ }^{\circ} \mathrm{C}$ multiples, which might help in signalling the temperature value, or the range of its values, that sometimes are assumed as critical for steel fire design.

In the following analysis, the reduction factor $k_{E, \theta}$ is used to calculate the reduced stiffness of the elements subjected to fire. Four cases were considered, by combining the location of the column (in an intermediate storey or at the top storey of a building) with the fire protection of the beams at the top of the column (cold or heated). It was assumed that the beams located at the storey below the heated column remain cold (naturally protected by the slab that they support), but the beams located at the top of the column may either be cold or heated. It should be stressed that the protection of these beams was considered $100 \%$ effective, that is, they were assumed to remain cold, which is a rather conservative assumption.

\section{Intermediate storey, cold beams}

Fig. 3 represents the structure used to analyse the influence of temperature on the elastic stability of a braced regular frame. The structure adopted should be thought of as a portion of a larger structure, developing above, below (this justifies the $1 / 2$ factor affecting the top and bottom beam stiffness $K_{b}$ ) and sideways, so that the present results are quite general. The use of similar reduced models for the stability analysis of regular frames is usual in the literature and we suggest, for instance, Ref. [1] for a justification of this procedure.

In this section it is assumed that the fire is confined to an intermediate storey and affects only the length of columns of that storey. The column lengths of the other storeys, as well as all the beams, are supposed to remain at room temperature, no thermal conduction was considered, so that their normal temperature stiffness is kept constant.

The buckling length of the column under consideration, column $\mathrm{AB}$, is influenced by the rotational stiffness of the nodes $\mathrm{A}$ and $\mathrm{B}$. This rotational stiffness depends upon the flexural stiffness of the members connected to the nodes A and B and on the type of joints. In a practical situation, the beams of the sub-assembly of Fig. 3 will not have built-in supports as shown. They will probably develop to the left and to the 


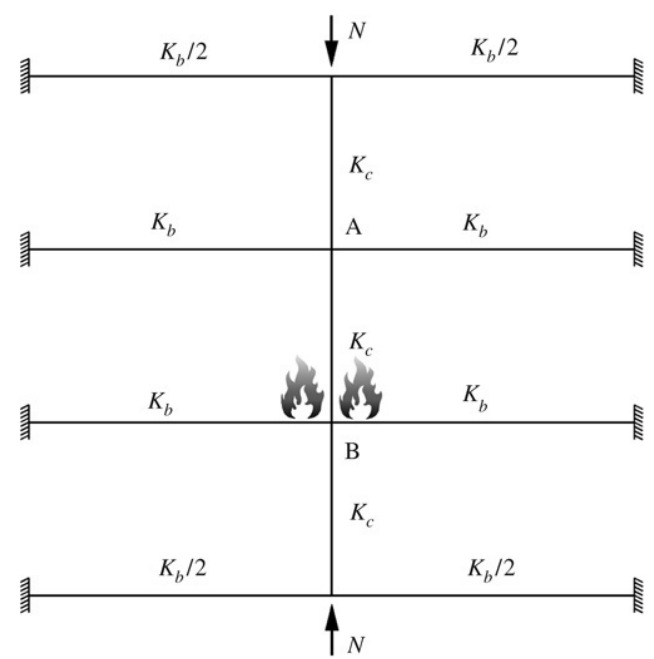

Fig. 3. Braced frame used in the analysis of a fire exposed intermediate storey.

right. Also, the column will develop in relation to other storeys above and below, and this will influence the rotational stiffness of the nodes $\mathrm{A}$ and $\mathrm{B}$ and the buckling length of column AB. Nevertheless, the model is considered to cover all these situations, because the analysis was done on the basis of the stiffness ratio

$\alpha=\frac{K_{b}}{K_{c}}$

where $K_{b}$ and $K_{c}$ are the beam and column stiffness coefficients defined by the ratio between the moment of inertia $I$ and the length $L$ of each element. In this way, the rotational stiffness of the nodes $\mathrm{A}$ and $\mathrm{B}$ is modified just by changing the value of $\alpha$, irrespective from what causes these changes, which may be due to changes in the values of $I$ and $L$ of the members, to changes in the type of joints or to different continuity conditions.

At elevated temperatures, it is assumed in the stability analysis that the stiffness of the intermediate column length decreases according to the reduction factor $k_{E, \theta}$ of Fig. 2.

The variation of the buckling length of the intermediate column is shown in Fig. 4 for $\alpha=1$, where the dots represent analytical results at multiples of $100{ }^{\circ} \mathrm{C}$. The appendix briefly describes the analytical procedure required for this and the subsequent three sections. The buckling length drops off from $0.686 \mathrm{~L}$ at room temperature to $0.5 \mathrm{~L}$ at $1200^{\circ} \mathrm{C}$. However, if the critical temperature is for instance $500{ }^{\circ} \mathrm{C}$, the buckling length is $0.583 \mathrm{~L}$, i.e. $16.7 \%$ higher than the Eurocode 3 allowed value $0.5 \mathrm{~L}$.

This difference between the Eurocode 3 and the exact curves of Fig. 4 is accentuated in Fig. 5 where values for the Euler buckling load $N_{f i, c r}$ are compared. The thick line in Fig. 5 represents buckling loads calculated with the Eurocode 3 rule (1), while the dots represent analytical Euler buckling loads $N_{f i, c r}$. At $500{ }^{\circ} \mathrm{C}$ the Eurocode 3 rule overestimates the buckling load by more than $36 \%$.

\subsection{Approximation of the buckling length}

Fig. 6 shows the variation of the buckling length as a function of the reduction factor $k_{E, \theta}$ and also some

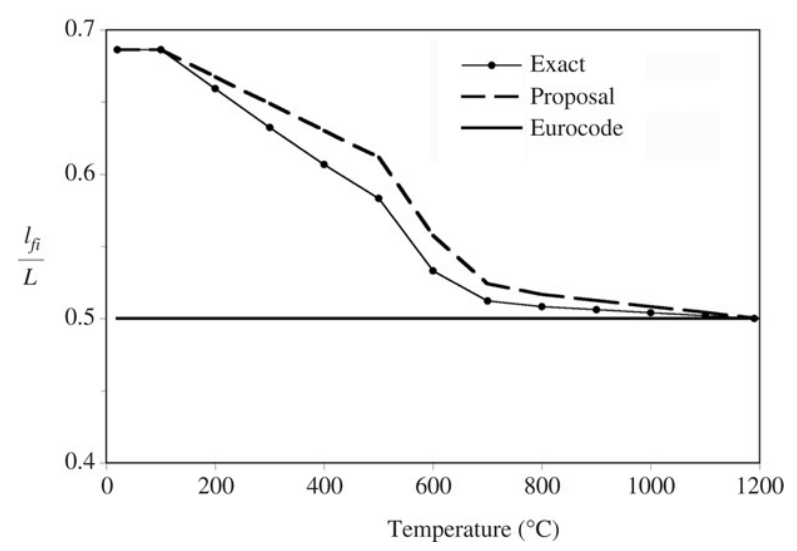

Fig. 4. Variation of the buckling length with temperature ( $\alpha=1$, cold beams).

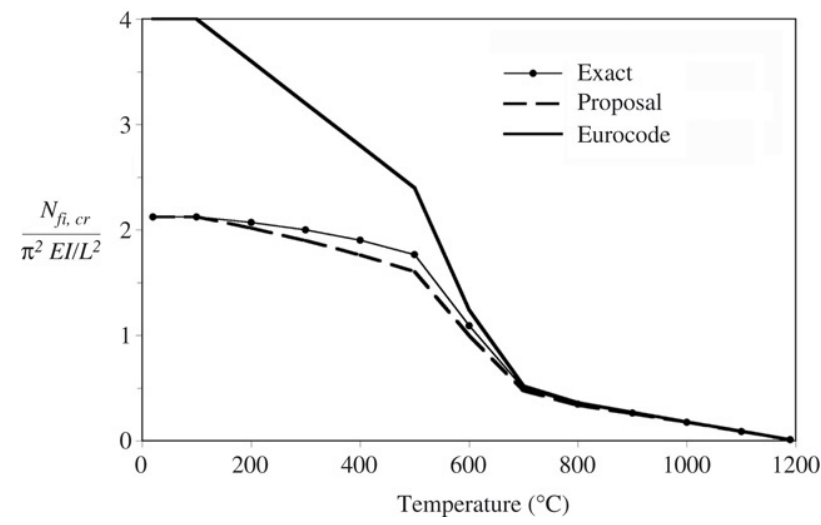

Fig. 5. Variation of the buckling load with temperature ( $\alpha=1$, cold beams).

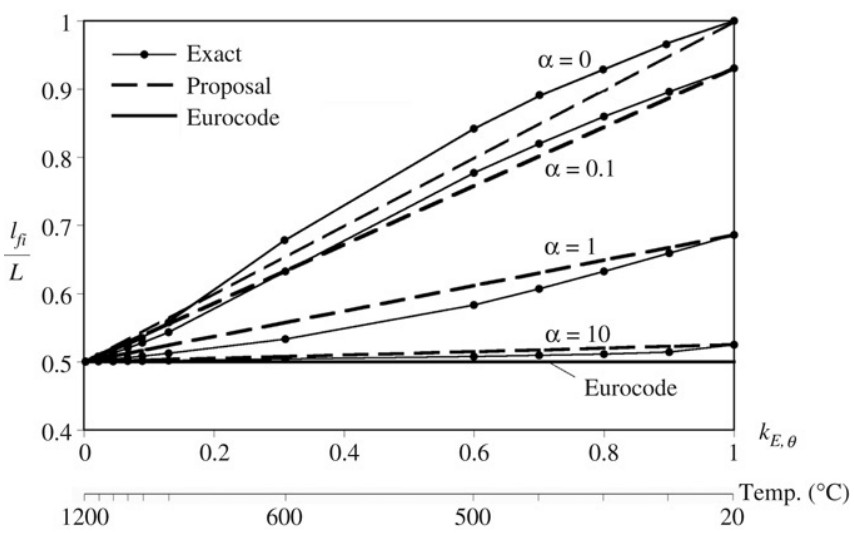

Fig. 6. Variation of the buckling length with $k_{E, \theta}$ (cold beams).

corresponding temperatures (once more, the dots match up $100{ }^{\circ} \mathrm{C}$ multiples). By observing that the buckling length varies almost linearly with $k_{E, \theta}$, the authors propose the following "linear" approximation to determine the buckling length $l_{f i}$ at temperature $\theta$

$l_{f i}=0.5 L+k_{E, \theta}\left(l_{20}-0.5 L\right)$

where $l_{20}$ is the buckling length at $20^{\circ} \mathrm{C}$.

The approximate formula (4) is represented in Fig. 6 by the dashed straight lines for four $\alpha$ values, where it can be seen that it is mostly on the safe side. In the previous Figs. 4 and 5, 


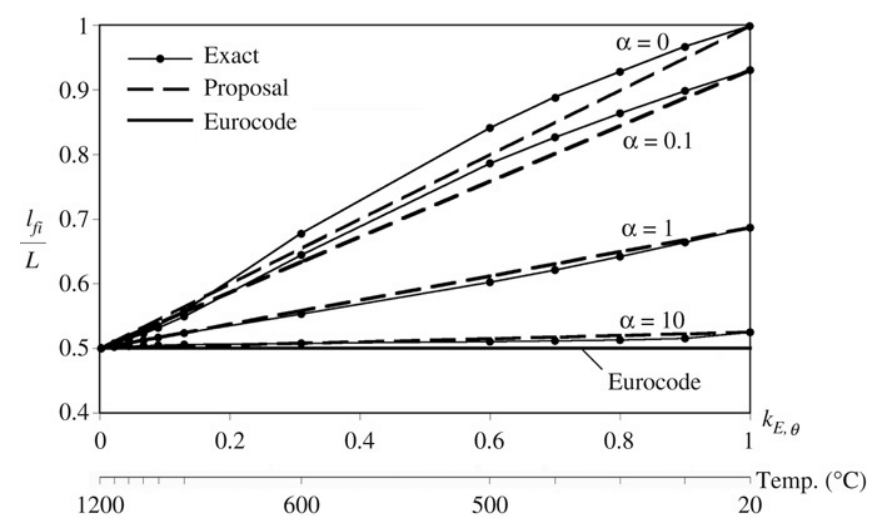

Fig. 7. Variation of the buckling length with $k_{E, \theta}$ (heated beams).

the dashed lines represent the approximate formula for $\alpha=1$. The buckling length $l_{f i}$, as given by formula (4), becomes $0.5 \mathrm{~L}$ when the temperature reaches $1200{ }^{\circ} \mathrm{C}$. This approximate formula is an improvement on the Eurocode 3 rule given by Eq. (1).

The buckling length is strongly influenced by the stiffness ratio $\alpha$, as shown in Fig. 6. The case $\alpha=0.1$ represents common simple beam-to-column joints with low rotational stiffness. (Note that in the case of perfectly hinged beam-tocolumn joints, $\alpha=0$, the buckling length is equal to $L$ at $20^{\circ} \mathrm{C}$. This limit case is realistic.) On the opposite side, $\alpha=10$ is an uncommon ratio, corresponding to very stiff beams, rigidly connected to the column.

For all values of $\alpha$, the buckling length tends to $0.5 \mathrm{~L}$ when the temperature tends to $1200{ }^{\circ} \mathrm{C}\left(k_{E, \theta}=0\right)$. Fig. 6 shows that the proposal (4) gives values of $l_{f i}$ close to the exact ones.

\section{Intermediate storey, heated beams}

In this section it is assumed that the intermediate storey is the fire compartment and that the floor beams are protected by the slab, but the superior beams are heated by the fire. This is a much more realistic assumption than the one of Section 2. Indeed, both the columns and the beams in a fire compartment are usually protected against fire in a more or less similar way. It is then realistic to assume a similar thermal action for both element types.

The structural sub-assembly in Fig. 3 is used once more to analyse this case, assuming that the fire is confined to the intermediate storey and affects not only the length of column of that storey but also the ceiling beams of the fire compartment. All the other beams and the column lengths of other storeys suffer no significant temperature increase and keep their normal temperature stiffness.

For this case, the variation of the buckling length of the intermediate column is shown in Fig. 7. The comparison with the former cold beams situation, Fig. 6, reveals that the buckling length in this latter case is slightly higher than in the former.

The comparison of Figs. 6 and 7 shows that the protection of beams does not have a significant effect on the column buckling length under fire conditions. The figures also show that the proposal (4) is suitable for both cases.

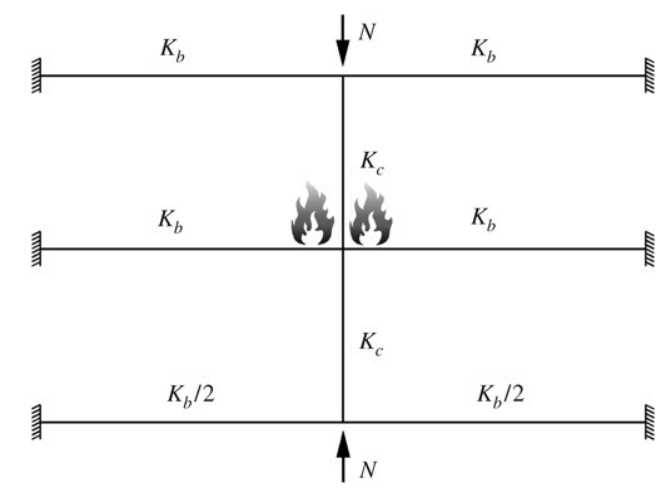

Fig. 8. Braced frame used in the analysis for a fire exposed top storey.

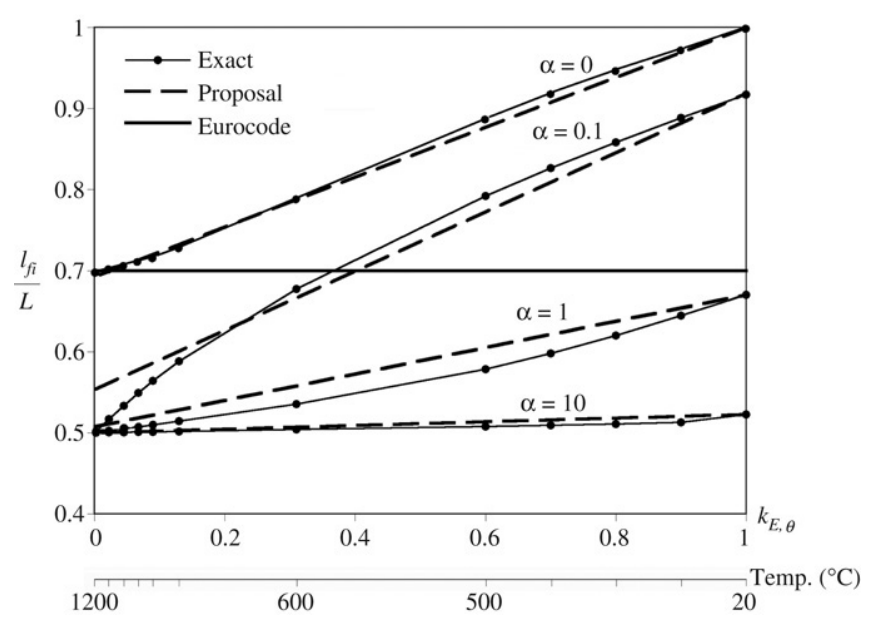

Fig. 9. Variation of the buckling length with $k_{E, \theta}$ (top storey, cold beams).

\section{Top storey, cold beams}

The sub-assembly model represented in Fig. 8 is used to analyse the case of fire confined to the top storey. The comments and assumptions made in Section 2 about the general applicability of the analysis hold also here.

In this section it is assumed that the fire affects only the top storey column length, while the column length of the storey below, as well as all the beams, suffer no temperature increase and keep their normal temperature stiffness.

The analytical results are represented again by dots in Fig. 9, where it may be seen that they significantly differ from Eurocode 3 rule (2).

Moreover, when the temperature tends to $1200{ }^{\circ} \mathrm{C}$, the buckling length does not converge to $0.5 \mathrm{~L}$ for every value of $\alpha$, for example the case $\alpha=0$ where the buckling length converges to $0.7 \mathrm{~L}$, meaning that the proposal (4) is not appropriate in this case.

Thus, as the temperature approaches $1200{ }^{\circ} \mathrm{C}$, the buckling length tends to the value $l_{1200}$, which depends on the stiffness ratio $\alpha$. For other temperatures, the buckling length varies between $l_{1200}$ and the buckling length $l_{20}$ at $20{ }^{\circ} \mathrm{C}$. A simple estimation of the buckling length for fire design is given by the following "linear" expression

$l_{f i}=l_{1200}+k_{E, \theta}\left(l_{20}-l_{1200}\right)$ 


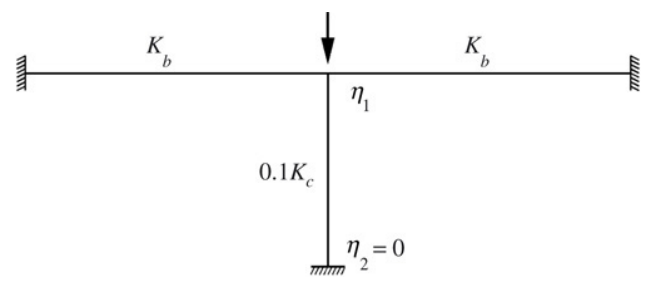

Fig. 10. Sub-assembly used to determine $l_{1200}$ (top storey, cold beams).

which, as a matter of fact, incorporates (4).

For the present case the buckling length $l_{1200}$ is determined by a stability analysis of the structure in Fig. 10. This may be easily achieved by the Wood method [8], also referred to in the informative Annex E of the draft version of Eurocode 3 [5] (not in the last versions of Eurocode 3 [4]). According to [5] and [8], the distribution factors $\eta_{1}$ and $\eta_{2}$ at the top and bottom of the column, Fig. 10, are defined in this case as

$\eta_{1}=\frac{0.1 K_{c}}{0.1 K_{c}+2 K_{b}}$

and

$\eta_{2}=0$.

The elastic buckling length $l_{1200}$ may be approximated by the expression given in [5]

$\frac{l_{1200}}{L}=0.5+0.14\left(\eta_{1}+\eta_{2}\right)+0.055\left(\eta_{1}+\eta_{2}\right)^{2}$

where the distribution factors $\eta_{1}$ and $\eta_{2}$ are given by (6) and (7).

The approximate solution (8) was used, together with (5), to determine the dashed lines in Fig. 9. The proposed linear solution, represented by the dashed straight lines, is a convenient and simple solution for this case too.

\section{Top storey, heated beams}

In this section, just like in Section 4, it is assumed that the floor beams in the top storey are cold (protected by the slab) whereas the top beams are exposed to the fire.

The sub-assembly model used in the analysis is again the one of Fig. 8, assuming that the fire is confined to the top storey and affects not only that storey column length but also the top beams. All other beams, as well as the length of column of the storey below, suffer no temperature increase and keep their normal temperature stiffness.

The results of the analysis, represented by the dots in Fig. 11, show that the buckling length now differs considerably from the values obtained on the basis of the Eurocode 3 rule (2).

In this case, the buckling length $l_{1200}$ is determined by a stability analysis of the structure in Fig. 12. This buckling length may also be approximated by expression (8) where the distribution factors $\eta_{1}$ and $\eta_{2}$ at the top and bottom of the column, Fig. 12, are defined in this case as

$\eta_{1}=\frac{K_{c}}{K_{c}+2 K_{b}}$

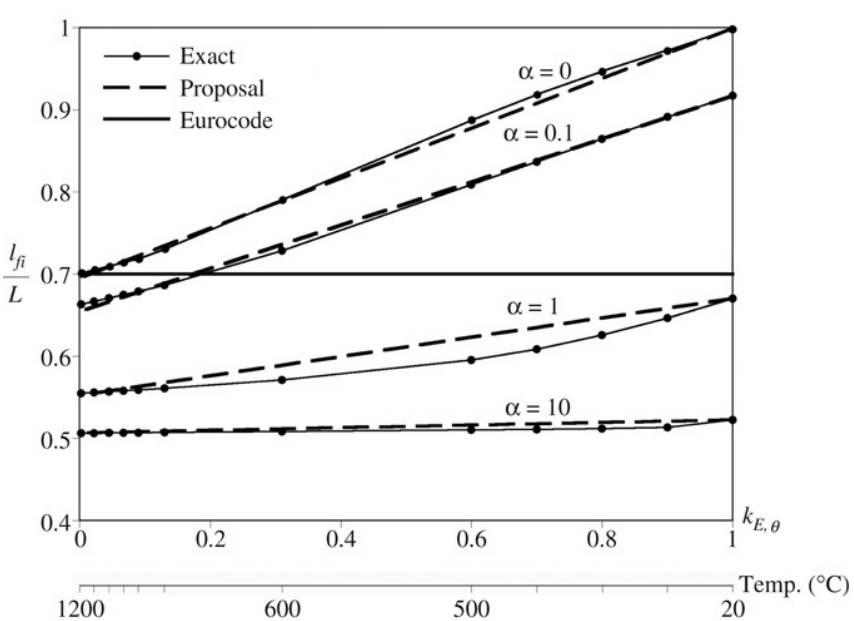

Fig. 11. Variation of the buckling length with $k_{E, \theta}$ (top storey, heated beams).

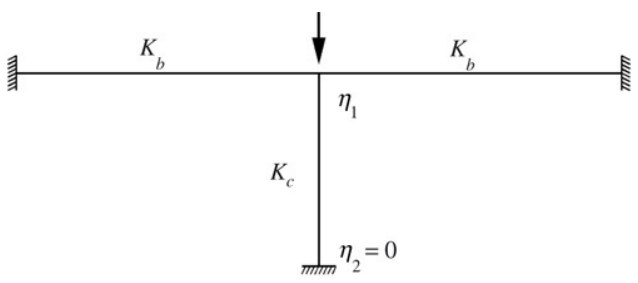

Fig. 12. Sub-assembly used to determine $l_{1200}$ (top storey, heated beams).

and

$\eta_{2}=0$.

Fig. 11 shows that the proposal (5), represented by the dashed lines, fits well with the analytical results, represented by the dots.

\section{Proposal (synthesis)}

This study shows that a linear interpolation of the buckling length between the value $l_{20}$ at $20{ }^{\circ} \mathrm{C}$ and the value $l_{1200}$ at $1200{ }^{\circ} \mathrm{C}$ is quite close to the exact solution. The buckling length for fire design may thus be approximated by the linear expression that takes the general form

$l_{f i}=l_{1200}+k_{E, \theta}\left(l_{20}-l_{1200}\right)$

where

$l_{1200}=\left\{\begin{array}{l}0.5 L \\ \text { in the case of fire in an intermediate storey } \\ 0.5 L+0.14 \eta L+0.055 \eta^{2} L \\ \text { in the case of fire in the top storey }\end{array}\right.$

and

$\eta=\left\{\begin{array}{l}\frac{K_{c}}{K_{c}+K_{b 1}+K_{b 2}} \\ \text { if the beams in the top storey are heated } \\ \frac{0.1 K_{c}}{0.1 K_{c}+K_{b 1}+K_{b 2}} \\ \text { if the beams in the top storey are cold. }\end{array}\right.$ 


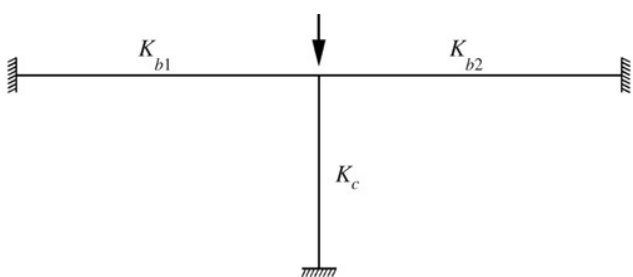

Fig. 13. Sub-assembly used to determine $l_{1200}$ in the case of the top storey.

The stiffness coefficients $K$ of the above expression refer to the beams and column (at $20^{\circ} \mathrm{C}$ ) in Fig. 13 in the general case where the top beams may have different stiffness $\left(K_{b 1}\right.$ and $\left.K_{b 2}\right)$.

\section{Conclusions}

The fire resistance of columns is very sensitive to the column slenderness. Therefore, the correct evaluation of the buckling length of columns to be used in fire situations is considered of great importance. Too conservative values are uneconomical, but unsafe values are unacceptable.

The analytical models used have shown that, for fire design, the indications of the Eurocode 3 part 1-2 for the buckling length of a steel column in a braced frame may be unsafe and are particularly unsafe in the case of fire in an intermediate storey. The paper also shows that the proposed linear solution fits well with the analytical results.

\section{Appendix}

The braced frame for the intermediate storey fire case (Fig. 3) has four degrees of freedom (DOF), associated to the rotations of the column-beam joints. Enumerating these DOF from top to bottom the elastic stiffness matrix is given by

$$
\begin{aligned}
& \boldsymbol{K}[N, \theta]=4 E K_{c} \\
& \times\left[\begin{array}{cccc}
\phi_{3}[u]+\alpha & \frac{1}{2} \phi_{4}[u] & 0 & 0 \\
\frac{1}{2} \phi_{4}[u] & \phi_{3}[u]+k_{E, \theta} \phi_{3}[\breve{u}]+2 \alpha \gamma & \frac{1}{2} k_{E, \theta} \phi_{4}[\breve{u}] & 0 \\
0 & \frac{1}{2} k_{E, \theta} \phi_{4}[u ̈] & \phi_{3}[u]+k_{E, \theta} \phi_{3}[u]+2 \alpha & \frac{1}{2} \phi_{4}[u] \\
0 & 0 & \frac{1}{2} \phi_{4}[u] & \phi_{3}[u]+\alpha
\end{array}\right]
\end{aligned}
$$

with the normalised axial load parameter for the cold and the exposed column lengths given respectively by $u=\frac{L_{c}}{2} \sqrt{\frac{N}{E I_{c}}}$ and $\breve{u}=\frac{u}{\sqrt{k_{E, \theta}}}$, the Livesley stability functions [6,7]

$\phi_{0}[u]=\frac{u}{\operatorname{Tan}[u]} ; \quad 3 \phi_{2}[u]=\frac{u^{2}}{1-\phi_{0}[u]} ;$

$4 \phi_{3}[u]=3 \phi_{2}[u]+\phi_{0}[u] ; \quad 2 \phi_{4}[u]=3 \phi_{2}[u]-\phi_{0}[u]$

and $\gamma$ is a parameter controlling the beam's exposure to fire, i.e., $\gamma=1$ in the case of cold beams and $\gamma=k_{E, \theta}$ in the case of fire exposed beams.

Similarly, the braced frame for the top storey fire case (Fig. 8) has three DOF, and the corresponding elastic stiffness matrix is given by

$\boldsymbol{K}[N, \theta]=4 E K_{c}$

$\times\left[\begin{array}{ccc}k_{E, \theta} \phi_{3}[\breve{u}]+2 \alpha \gamma & \frac{1}{2} k_{E, \theta} \phi_{4}[\breve{u}] & 0 \\ \frac{1}{2} k_{E, \theta} \phi_{4}[\breve{u}] & \phi_{3}[u]+k_{E, \theta} \phi_{3}[\breve{u}]+2 \alpha & \frac{1}{2} \phi_{4}[u] \\ 0 & \frac{1}{2} \phi_{4}[u] & \phi_{3}[u]+\alpha\end{array}\right]$.

The critical values for $N$ are obtained from a (nonlinear) eigenvalue analysis.

\section{References}

[1] Bazant ZP, Cedolin L. Stability of structures: Elastic, inelastic, fracture and damage theories. Oxford University Press; 1991.

[2] CEN/TC 250/SC 3. Draft EC 3. Part 1.2 Structural fire design. Background document 10.1. Technical note 2.9 — Buckling length of columns in braced frames to be used in member analysis. May 1992.

[3] European Committee for Standardization (CEN). Eurocode 3 (EN 1993-12) - design of steel structures, part 1.2: general rules - structural fire design. Brussels, Belgium; 2004.

[4] European Committee for Standardization (CEN). Eurocode 3 (EN 1993-11) - design of steel structures, part 1 - general rules and rules for buildings. Brussels, Belgium; 2005.

[5] European Committee for Standardization (CEN). Eurocode 3 (ENV 19931-1) - design of steel structures, part 1 - general rules and rules for buildings. Brussels, Belgium; 1992.

[6] Livesley RK. Matrix methods of structural analysis. 2nd ed. Pergamon Press; 1975.

[7] Reis AJ, Camotim D. Estabilidade estrutural [Structural stability]. Lisbon (Portugal): McGraw-Hill; 2000 [in Portuguese].

[8] Wood RH. Effective lengths of columns in multi-storey buildings. The Structural Engineer. London 1974;52(7, 8, 9):235-44; 295-302; 341-346. 